\title{
Electropolishing of re-melted SLM stainless steel 316L parts using deep eutectic solvents: $3 \times 3$ full factorial design
}

\author{
K. Alrbaey ${ }^{1}$, D.I. Wimpenny ${ }^{2}$, A. A. Al-Barzinj $j^{3,4}$, and A. Moroz ${ }^{1}$ \\ ${ }^{1}$ School of Engineering and Sustainable Development, De Montfort University, the \\ Gateway, Leicester, LE1 9BH UK. T: +44 (0)116 2506649 E-mail: \\ AMoroz@dmu.ac.uk \\ ${ }^{2}$ Manufacturing Technology Centre, Coventry, UK \\ ${ }^{3}$ Chemistry Department, University of Leicester, Leicester, UK LE1 7RH. E-mail: \\ Aa643@le.ac.uk \\ ${ }^{4}$ Physics Department, University of Salahaddin, Arbil, Iraq
}

\section{Summary}

This three levels three factors full factorial study describes the effects of electropolishing using deep eutectic solvents on the surface roughness of re-melted 316L stainless steel samples produced by the Selective Laser Melting (SLM) powder bed fusion additive manufacturing method. An improvement in the surface finish of re-melted stainless steel 316L parts was achieved by optimizing the processing parameters for a relatively environmentally friendly ('green') electropolishing process using a Choline Chloride ionic electrolyte. The results show that further improvement of the response valueaverage surface roughness $(R a)$ can be obtained by electropolishing after re-melting to yield a 75\% improvement compared to the as-built $R a$. The best $R a$ value was less than $0.5 \mu \mathrm{m}$, obtained with a potential of 4 volts, maintained for $30 \mathrm{mins}$ at $40 \mathrm{C}^{\circ}$. Electropolishing has been shown to be effective at removing the residual oxide film formed during the re-melting process. The material dissolution during the process is not homogenous and is directed preferentially towards the iron and nickel, leaving the surface rich in chromium with potentially enhanced properties. The re-melted and polished surface of the samples gave an approximately 20\% improvement in fatigue life at low stresses (approximately 570MPa). The results of the study demonstrate that a combination of re-melting and electropolishing provides a flexible method for surface texture improvement which is capable of delivering a significant improvement in surface finish whilst holding the dimensional accuracy of parts within an acceptable range. 


\section{Introduction: electropolishing process using ionic liquids}

Electropolishing is an electrochemical technique based on controlled dissolution which has been shown to be useful for improving the surface topography of a range of metallic materials [1]. Generally, the electro chemical process (ECP) is a post-processing method that can be used for surface property improvement. A range of metallic materials can be polished including copper, nickel or titanium, however the majority of research has been conducted on stainless steel alloys [1-2]. It is worth mentioning that in electropolishing in general two surface phenomena happen, namely anodic levelling and anodic brightening. Anodic levelling results from the different dissolution rates of the peaks and valleys of the surface texture of the substrate due to the primary current distribution in the cell [1]. In these cases, the amount of the primary current distribution has a significant effect on the material dissolution (mass transfer), which leads to a reduction in the surface roughness by several microns [2][3]. Anodic brightening improves the surface roughness due to control of the dissolution rate for the metal microstructure [4$10]$.

After being patented in 1930 electropolishing of stainless steel and other metal alloys using mixtures of concentrated sulphuric and phosphoric acids was undertaken worldwide on a commercial scale. However, the process is hazardous for both the environment and workers involved in this technique. In addition extensive gas formation and low current efficiency are associated with this process [11]. Therefore investigations have been undertaken utilising ionic liquid reactions, such as catalysis, nanomaterials, electrodeposition and striping, which are greener alternatives to the current toxic, polluting and unstable organic solvents [12].

Room temperature ionic liquids (RTIL) have attractive properties for use in electrochemical polishing, such as thermal stability, high polarity, high viscosity, natural conductivity and a wide electrochemical processing window [13]. Abbott and colleagues introduced a new alternative for electropolishing based on a mixture of choline chloride and ethylene glycol, a type III deep eutectic solvent called Ethaline 200 [6]. This approach gave considerable benefits, including high current efficiency, negligible gas evolution at the anode/solution interface and the use of a relatively benign liquid compared to the acid mixture solution normally used [14]. Nowadays, applications of ionic liquids range from fuel desulfurization to organic synthesis, catalysis, 
electrochemistry and precious metal processing. Ionic liquids, in principle, offer many advantages over conventional organic solvents but very few have been developed to full commercial exploitation although several have reached the pilot stage[15][16].

Recently, Abbott and colleagues have introduced the concept of Deep Eutectic Solvents (DES) as a sub-category of ionic liquids [6, 13, 14, 17-19]. The DES is a fluid resulting from the mixing of two or three components which are capable of combining each other, frequently through hydrogen bond interactions. In such cases the eutectic mixture formed can be characterised by the lowest melting point, compared with the melting point of each individual components [17, 17b].

Modern electropolishing of stainless steel is performed on a commercial scale using a mixture of phosphoric acid and sulphuric acid, despite the well documented drawbacks of the process [20]. It has been shown that 316 stainless steel parts can be successfully electropolished in Choline Chloride (ChCl) [21]. Using this approach it was demonstrated that the oxide film can be removed at a lower current than typically employed with aqueous acidic solution and also the micro-roughness can be reduced to less than $100 \mathrm{~nm}$. Other researchers have reported that ionic liquids are non-corrosive and moisture stable compared to aqueous acid solutions for electropolishing [13] [22]. The process employs relatively safe materials, such as choline chloride (known as provitamin), which has been used for many years in chicken feed. The technology has been demonstrated at a pilot plant scale (50 litres) and then at a commercial scale (1300 litres). The results of empirical trials have indicated that the cost of electropolishing using DESs is comparable with existing phosphoric acid or sulphuric acid electrolytes due to the improved current efficiency which was shown to be about four times greater than an equivalent aqueous system [23].

The main aim of this study was to use DES electropolishing as a more environmentally ("green") friendly electropolishing process to reduce the surface roughness of 316L stainless steel samples produced by SLM. The samples had already been subjected to laser re-melting and by optimising the electropolishing parameters it was hoped to further improve the surface quality with a minimal material removal. 


\section{Materials and Methods}

Electropolishing is an electrochemical process, which includes controlled dissolution of the atoms of metals/alloys from their surface when they submerged in an electrolyte. According to Faraday's law, the amount of material removed from the surface is proportional to the passage current (electric charge) through the cell. The amount of electric charge is $Q=I^{*} T$, where $I$ is electric current and $T$ is time [7].

The electropolishing trials were divided into 4 key stages;

1. Preparation of the SLM samples.

2. Liquid preparation.

3. Electropolishing of stainless steel 316L samples obtained after re-melting stage.

4. Physical properties measurement.

\subsection{Preparation of the SLM samples}

All the experiments in this study have been conducted using samples made with a Renishaw AM125 machine (Renishaw PLC, Gloucestershire UK), employing method described in [24]. The Renishaw AM125 machine has the following specification; build

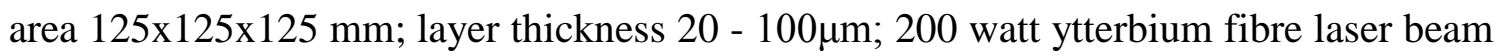
with a spot size of $\sim 35 \mu \mathrm{m}$ at the powder bed surface;

In this study, Stainless Steel 316L (SS 316L) powder, particle size ranges from 15$45 \mu \mathrm{m}$ was used to manufacture the samples. The material is processed within an inert gas (argon) environment. The chemical composition of the SS 316L powder specified by Renishaw is as following: Iron (Fe) 63.05-67.75 Wt\%; Chromium (Cr) 17.50-18.00 Wt\%; Nickel (Ni) 12.50-13.00 Wt\%; Molybdenum (Mo) 2.25-2.50 Wt\% ; Manganese (Mn) < 2.00 Wt\%; Silicon (Si) < 0.75 WT\%; Copper $(\mathrm{Cu})<0.50 \mathrm{Wt} \%$; Nitrogen $(\mathrm{N})<$ $0.10 \mathrm{Wt} \%$; Oxygen (O) <0.10 Wt\%; Carbon (C) $<0.03 \mathrm{Wt} \%$; Phosphor (P) $<0.025$ $\mathrm{Wt} \%$; Sulphur (S) $<0.010 \mathrm{Wt} \%$.

The sample dimensions were $(4,10$, and 30$) \mathrm{mm}$, and they had an initial surface roughness $(R a)$ measured in the range 10 to $17.5 \mu \mathrm{m}$, due to the stair effect, built examples for $\left(15^{\circ}, 30^{\circ}\right.$ and $\left.45^{\circ}\right)$ are illustrated in Figure 1 . The samples were re-melted on the top surface, using the optimal parameters at the manufacturing stage [24]. The samples were removed from their supports and re-mounted to be re-melted with their top 
surfaces horizontally. The parameters used for re-melting were as follows: laser power 180Watt, scan speed: $500 \mathrm{~mm} / \mathrm{min}$; distance between the lens of laser source and the substrate: 128mm; shielding argon gas: $4 \mathrm{~L} / \mathrm{min}$; the focal length of lens: $120 \mathrm{~mm}$; beam diameter at lens: 16mm; hatch spacing: 400 micron; beam spot size: approximately $1 \mathrm{~mm}$. After completion of the re-melting process and inspection, the top (upward facing) surface of the samples was assessed for surface roughness, topography and porosity. The surface roughness was found to be approximately $(1.4 \pm 15 \% \mu \mathrm{m})$.

\subsection{Liquid preparation}

This study was carried out using Choline chloride (ChCl) (Aldrich, 99\%) and Ethylene glycol (EG) (Aldrich, >99\%) in a 1:2 ratio by weight. The Choline chloride was first recrystallised, filtered and dried whereas the Ethylene glycol was used as received. 5\% and $10 \%$ oxalic acid was added to improve the properties of the liquid formed. The components were mixed first and then stirred at $80^{\circ} \mathrm{C}$, until a homogeneous mixture was obtained [25].

\subsection{Physical properties measurements}

Viscosity measurements. The viscosity of the liquid was investigated as function of temperature. The temperature range used was 20-75 ${ }^{\circ} \mathrm{C}$. Brookfield DV-E Viscometer (Brookfield Instruments, USA) fitted with a temperature probe was used. The liquid was first heated up to $80^{\circ} \mathrm{C}$ and then the measurements of viscosity were taken from that temperature, all the way down to $20^{\circ} \mathrm{C}$, see Figure $2 \mathrm{~A}$. The liquid was allowed to cool naturally (i.e. at room temperature) without use of any cooling system. The viscosity measurement was obtained using a spindle attachment. The measurements were taken with the temperature maintained constant within the error of $\pm 1{ }^{\circ} \mathrm{C}$. An average of three readings of viscosity was used for the analysis.

Conductivity measurements. The conductivity of liquid was measured as function of temperature. The temperature range used was $20-75{ }^{\circ} \mathrm{C}$. The instrument used was a Jenway 4510 conductivity meter fitted with an inherent temperature probe (cell constant $=1.01 \mathrm{~cm}^{-1}$ ). All mixtures were heated up to $80{ }^{\circ} \mathrm{C}$ and the measurements were taken from $20{ }^{\circ} \mathrm{C}$ then on up to $75^{\circ} \mathrm{C}$, Figure 2B. All conductivity measurements were 
recorded at exactly the same temperatures as used for the viscosity trial and for the same eutectic composition using SLM samples from the same production batch.

Cyclic voltammetry. Cyclic voltammetry investigation was carried out using an (Autolab PGSTAT12) potentiostat controlled with GPES2 software. A three-electrode system was used, consisting of the stainless steel 316L test sample as the working electrode and a silver reference- electrode. All cyclic voltammograms, Figure 3, were taken at $30{ }^{\circ} \mathrm{C}$ and at a scan rate of $20 \mathrm{mVs}^{-1}$, in order to see the effect of increasing oxalic acid content and to observe the height and peak position of the redox interaction which are all important during the electropolishing and deposition process. The samples of liquids for this test were taking from the same batch as that used in the previous tests. The results showed that the solutions become more reactive proportionally with the temperature rise. It was also noted that this trend tends to be diminished in liquids that have less oxalic acid.

\subsection{Electropolishing procedure}

The trials have been performed on a number of stainless steel 316L SLM samples manufactured using the parameters previously described [24]. Specific areas were selected to be polished and acrylic resin was used to mask the surrounding, unpolished, area.

The result of the polishing process on the surface quality of SLM components can be affected by number of factors. The main expected factors were: the potential source, polishing duration, temperature, cell component (concentration), current density and the method of stirring [26][27]. The set of parameters has been selected according to the most important factors established in preliminary trials, as follows: 1) source potential: started from 4 volt and changed to 6 and 8 volt respectively; 2) duration time: started from 30 minutes and changed to 45 and 60 min respectively; 3) temperature: from $20 \mathrm{C}^{\circ}$ and changed to 40 and $60 \mathrm{C}^{\circ}$ respectively. Other factors kept constant as follows: type of liquid and liquid concentration (Ethaline 5\% oxalic acid) and method of stirring - rate approximately 300rpm, as recommended in [27][28]. 
The effect of selected parameters on the response value (1) surface roughness and (2) loss in weight (depth of polishing area) have been investigated using classical full factorial experimental 3x3design set up as shown in the Table 2.

At the beginning of the experiments, the work pieces were attached with the finishing region (anode), whereas the negative terminal of cell was connected to a cathode fabricated from a titanium radium mesh (selected for its stability). The two poles (anode, cathode) were kept immersed into electrolyte liquid (Ethaline 5\% Oxalic acid).

In this study, the response values; surface roughness Ra and the loss in weight, from which the polishing depth (thickness of material removed) can be deduced, were obtained as the result of passing the electric current through the cell, using specific parameters. The anodic dissolution of specimens was measured at different potential, time duration and temperature, as shown in Table 3. Each of the setups was replicated three times to find the average results for the response values.

\section{Results and discussion}

The surface quality of the polished samples depends on using the optimal conditions for current density, which is related to the cell parameters. Therefore, the overall surface quality of anodic surface can be characterized by three parameters, which statistically can be treated as the response factors. They are: (1) average surface roughness, (2) surface defects (pitting) and (3) surface brightness. The surface roughness was measured using of a Stylus profilometer and in addition the depth of polished area was calculated. Standard regression method integrated in any experimental design software (DOE) has been employed to calculate the interaction of the average results of these response values: surface roughness $(R a)$ and the depth of polishing area. The errors were calculated and tabulated as shown in Table 3. The other response factors (pitting \& brighten) are qualitative and were characterised using optical techniques.

Table 3 shows the variation in the surface roughness and polishing depth with the deviation in voltage, duration of time interval and the liquid temperature. For all cases, three trials have been conducted and averaged to provide better accuracy. The errors were acquired for further analysis and comparison. After the re-melting procedure, the surface roughness $R_{a}$ was observed of about $1.4 \pm 15 \% \mu \mathrm{m}$ and $R_{z}$ is about $7 \pm 15 \% \mu \mathrm{m}$. 
For a good polishing, the resulting value for the depth should be in a range of $R_{z}$. Although, the results of majority of samples display good surface roughness, in some samples the required polishing depth was exceed. This, in turn, affects the accuracy of the part's dimensional tolerance. Profilometer results (see Table 3) showed that the best results for the surface roughness was achieved at a temperature of $40 \mathrm{C}^{\circ}$, time interval 60 minutes and voltage $6 \mathrm{~V}$. The surface roughness obtained at these conditions is $0.34 \mu \mathrm{m}$ microns. But the polished depth was $19.94 \mu \mathrm{m}$ for these conditions which exceeds the required polishing depth. In these cases, the reduction of process duration can result in a decrease in polishing depth.

Reducing the duration of the polishing process from 60 to 30 minutes and keeping the temperature at $40 \mathrm{C}^{\circ}$ and voltage at $6 \mathrm{~V}$, the polished depth changed to 10.8 $\mu \mathrm{m}$ and the surface roughness at these conditions was $0.34 \mu \mathrm{m}$ which is a favourable result. Furthermore, when the time was maintained at 60 minutes and the voltage was reduced from $6 \mathrm{~V}$ to $4 \mathrm{~V}$ at the same temperature of $40 \mathrm{C}^{\circ}$, the polished depth was 10.3 $\mu \mathrm{m}$ and the surface roughness was $0.34 \mu \mathrm{m}$. According to obtained results, the best response factors can be achieved with range of cell parameters such as $4 \mathrm{~V}$ to $6 \mathrm{~V}$ at constant temperature $40 \mathrm{C}^{\circ}$ and when the polishing duration ranges between 30 to 60 minutes.

\subsection{Current density}

The diagrams in Figure 4 show how the recorded current density varies with time and temperature during the trials. The current density is in $\mathrm{mA} / \mathrm{cm}^{2}$ and is illustrated for 3 different voltages (4, 6 and 8Volt) measured for 3 different time intervals (30, 45 and 60) minutes.

In Figure 4, it can be seen that similar patterns can be observed in variations for all time intervals used in this experiment. For temperature $60 \mathrm{C}^{\circ}, 8$ volts, Figure 4A, the current density keeps fluctuating with time. Unstable variations show peak and valley behaviour. The current density is observed within average range from $83 \mathrm{~mA} / \mathrm{cm}^{2}$ to 91 $\mathrm{mA} / \mathrm{cm}^{2}$. For 6 volts, the fluctuations of current density are much lower than that for 8 volts. It can also be seen that the pattern of the peak fluctuations are similar regardless of the time. The average of current density varied between $30 \mathrm{~mA} / \mathrm{cm}^{2}$ to $45 \mathrm{~mA} / \mathrm{cm}^{2}$. For 4 volts, the current density fluctuates in the minimum pattern and shows a similar pattern 
of fluctuations as well for the three different time intervals. The average of current density was within a range of $16 \mathrm{~mA} / \mathrm{cm}^{2}$ to $26 \mathrm{~mA} / \mathrm{cm}^{2}$.

It can be seen that the fluctuations of peaks for $40 \mathrm{C}^{\circ}$, Figure $4 \mathrm{~B}$, are less than that on the previous diagrams for $60 \mathrm{C}^{\circ}$, Figure 4A. Regardless of time duration of the trial, the variations in the patterns remained similar to $60 \mathrm{C}^{\circ}$ for all 3 different voltages used in this experiment. The highest current density was observed for the 8 Volts where it was in the range of $44 \mathrm{~mA} / \mathrm{cm}^{2}$ to $58 \mathrm{~mA} / \mathrm{cm}^{2}$. The minor fluctuations and peaks were observed for current density against time. For 6 Volts, the current density indicates more stable pattern with minor fluctuation, which were observed in time intervals used in the trial, and it was observed in the range of $18 \mathrm{~mA} / \mathrm{cm}^{2}$ to $24 \mathrm{~mA} / \mathrm{cm}^{2}$. For 4 volts, the current density was in the range of $8 \mathrm{~mA} / \mathrm{cm}^{2}$ to $13 \mathrm{~mA} / \mathrm{cm}^{2}$ and shows almost no fluctuations.

Figure $4 \mathrm{C}$ (20 ${ }^{0}$ temperature) indicates there is less fluctuation in the variation of current density against time intervals for the three different voltages used in this study. At 8 volts, the pattern of fluctuations is minimal compared to the pattern observed in the previous two graphs $4 \mathrm{~A}$ and $4 \mathrm{~B}$ and is in the range from $16 \mathrm{~mA} / \mathrm{cm}^{2}$ to 23 $\mathrm{mA} / \mathrm{cm}^{2}$. For 6 volts, the variations and peaks are minimal as well and it can be seen that current density varies against time in a stable fashion between $10 \mathrm{~mA} / \mathrm{cm}^{2}$ to 14 $\mathrm{mA} / \mathrm{cm}^{2}$. A similar kind of pattern is observed with lower current density for the 4 volts. Also a smooth pattern of variations of current density is observed within the range of 4 $\mathrm{mA} / \mathrm{cm}^{2}$ to $8 \mathrm{~mA} / \mathrm{cm}^{2}$.

Comparing the results of the three previous graphs with the results in Table 3 indicates that the variation of the response values (surface roughness and depth of polishing) are highly depending on the amount of dissolved material (current density). Moreover, these results may explain the reason for increased surface roughness at high current density, which may lead to non-homogeneous material dissolving (see Table 3). Thus, the process parameters should be set to control the amount of metal removed within arrange of current density between $10 \mathrm{~mA} / \mathrm{cm}^{2}$ and $20 \mathrm{~mA} / \mathrm{cm}^{2}$ at a constant temperature $40 \mathrm{C}^{\circ}$. This can be obtained within the range of voltage between 4 to 6 volts and process duration between 30 to $60 \mathrm{mins}$. These results demonstrate that is it possible to maintain the dimensional tolerances of the parts and generate a surface roughness (Ra) of about $0.35 \mu \mathrm{m}$. 


\subsection{Statistical analysis}

The results have been analysed for 2 response factors and the findings are shown in Table 4. The table indicates the impact of selected factors on the response variables and the Pareto diagrams (Figure 5-6) illustrate graphically the ranks of selected factors.

The interaction of the factors in Table 4 can be also illustrated in a graphical form. The Figure 5 indicates the results for roughness Ra as the response variable. As can be seen, the potential (variable A), its square (AA), its interaction with temperature (term AC) and the interaction of its square (AA) with temperature C (term ACC) - the read colour in the Pareto diagram in Figure 5 - indicates a very good confidence level of less than 0.0001. The impacts of other factors, including the linear impact of time (B) and temperature (C) are small and do not indicate a good confidence level. Quantitatively, the individual impact of these factors is an order of magnitude less than the first four combined factors (A, AA, AC and AAC). R-square for this model is 0.91 . This means that all other remaining factors, not taken into account in this 3-factorial model, are responsible just for 9\% of impact, which means that potential (A), temperature (c) and time (B) play 10-times more significant role in forming the surface roughness $\mathrm{Ra}$, that remaining factors.

On the basis of the data in Table 4 for roughness $R a$, the statistical model for the prediction of the average surface roughness ( $R a$-hat) can be written as:

$$
\hat{R a}=0.377+0.165 A+0.134 A A+0.104 A C+0.772 A A C
$$

where $A$ is the potential, $C$ is temperature; $R a$-hat is predicted average roughness. The correctness of this model and its limitations are illustrated in Figure 7. Figure 7A shows good linear dependence between actual and predicted roughness values. Figure 7B indicates that there is non-uniform distribution of residuals in the area of large actual $R a$ and, therefore, some other factors need to be included. However the overall correctness of model is $\mathrm{R}^{2}=0.89$, which is good for given that three factors are taken into account.

On the other hand, the effect of these parameters on calculated polishing depth in the sense of overall outcome representing by R-square, Table 4, indicates better statistical significance. The R-square is 0.98 and adjusted R-square is 0.97 which can be interpreted statistically as very good. However, the impact of considered variables and 
their combinations on calculated polishing depth, Figure 6, differs significantly from analogous impact on the average roughness $R a$, Figure 5 . As it shown in Figure 6, the potential (A) still has the greatest impact, however the linear impacts of temperature (C) and time (B) take second and fourth place in the diagram and both have acceptable significance. Quadratic effects for the variable interactions AC, AA, AB, BC, and CC are observed as statistically significant, together with some cubic effects of AAC, BCC and $\mathrm{ABC}$. Cubic impact $\mathrm{AAB}$ is confident at the level of 0.08 . The overall fit of this model is also indicated in Figure 7C,D where the residual analysis is illustrated.

On the basis of the data in Table 4 for calculated polishing depth (PD), the statistical model for the PD-hat prediction can be written as:

$$
\begin{aligned}
& \hat{P D}=15.0+14.4 A+8.0 B+11.3 C \\
& +5.6 A A+11.3 A C+5.22 A B+4.4 B C+3.0 C C+ \\
& 4.4 A A C-4.2 B C C+2.7 A B C+1.8 A A B
\end{aligned}
$$

where $A$ is the potential, $C$ is temperature; $P D$-hat is predicted polishing depth. Correctness of this model and its limitation are illustrated in Figure 7. Figure 7C shows good linear dependence between actual and predicted values PD. Figure 7D indicates that there is non-uniform distribution of residuals in the range of large actual PD and some other factors need to be included. However, overall correctness of model is $\mathrm{R}^{2}=0.97$, which is extremely good for three factors.

The results obtained from the trial show that the ranges of selected factors (potential, time and temperature) are in a good range to affect the response factors. The overall analysis indicates that the potential and the temperature have the highest impact on both response factors (surface roughness and polishing depth), whereas the third factor (time) showed less effects as demonstrated on Pareto diagrams, Figure 5 and 6. The best results are obtained for the potential range 4 to 5.5 volt, time interval 30 minutes, at constant temperature $40 \mathrm{C}^{\circ}$. This set of parameters indicates enough ability to control the metal dissolution and generate the current density in range between $10 \mathrm{~mA} / \mathrm{cm}^{2}$ and $20 \mathrm{~mA} / \mathrm{cm}^{2}$, which leads to more planar surface. This range may facilitate maintaining accuracy of part dimensions and give less than $0.4 \mu \mathrm{m}$ for the surface 
roughness $(R a)$. Figure 8 illustrates the results of surface roughness improvement, mainly for re-melting followed by electropolishing.

\subsection{Surface topography}

Surface topography has been examined by using scanning electron microscope (SEM) combined with Energy Dispersive X-ray analysis (EDX). SEM was employed to understand the characteristics of defects observed during the polishing process, whereas EDX was exploited to analyse the elemental/percentage composition of each samples surveyed before and after the polishing procedure. In our case of stainless steel (SS 316L), the characteristics of the surveyed surfaces vary due to deviation in the cell parameters. This parameter deviation has significant effect, and the relation between the parameters needed be optimised for control the current density, which in turn determines whether homogenous metal/alloy dissolution is achieved.

The majority of surveyed samples show a good surface finish, but some pitting has been detected, connected with exposure to higher voltage and temperature (8 volt at $60 \mathrm{C}^{\circ}$ ) as illustrated in Figure 9.

It is well known that the key of the electropolishing method is the difference in current density across the microscopic surface profile (peak and valley) and that the current density is greater on the peaks than in the valleys. In case of 8 volt at $60 \mathrm{C}^{\circ}$, the rate of current density was too high and fluctuated (see Figure 4) leading to a faster metal dissolution (non-homogenous dissolving) and an increase in the viscous layer interface of the polished surface. This phenomenon (high rate dissolution) tends to leave the surface with a pitting and a poor surface finish. It also leads to an increase in the depth of the polished area beyond $60 \mu \mathrm{m}$, which is undesirable due to the loss of dimensional accuracy of the parts. In this case, there are two main ways which can be used to overcome the problem of excessive current density; the first method is to reduce the source potential or temperature (as shown in Figure 4 and the second method it to increase the resistance of the liquid by reducing the proportion of oxalic acid addition (however, this it not within the scope of this study).

A reduction in the source potential from 8 to 6 volt and temperature from $60 \mathrm{C}^{\circ}$ to $40 \mathrm{C}^{\circ}$ demonstrated a significant effect for various time intervals between 30 to 60 minutes, due to the change of the current density properties (less fluctuation and values 
indicated in Figure 4). The control of these properties is critical to achieve proper control of mass transport, which is required for homogenous metal/alloy dissolution during electropolishing process, which in turn results in an acceptable surface finish, as shown in Figure 9.

A reduction in current density may be preferable, since it leads to a more planer and defect free surface (as illustrated in Figure 10). Some samples showed that the depth of polished area has increased by more than required depth (less than $10 \mu \mathrm{m}$ ). In these cases, the required dimensional tolerance is not maintained. In addition, the samples exposed to polishing at a constant $20 \mathrm{C}^{\circ}$ and 4 volts with processing time between 30 to 60 minutes demonstrated pitting on the polished area, as illustrated in Figure 11.

The pitting phenomena can be explained by to two different mechanisms. One possibility is that applying a potential that is less than the required potential (in this case 4 volt or less) leads to the formation of a thin viscous film on the part surface during electropolishing. At the beginning of the electropolishing process (high current density, see Figure 4) the dissolution of material results in formation of cations that move through the viscous film to the solution, leaving some vacancies at the metal-film interface. When the vacancy concentration rises sufficiently, due to the low current density, it can lead to a detachment of the ion-conducting film from the surface and then the cations can merge to form the voids. This process can be avoided by keeping the potential as high as possible, ensuring that the anions in the film are kept pressed against the interface of metal-film (polished surface). The second explanation is that the pitting occurs because of gas bubbles on the polished surface. In such cases the surface can be obscured by bubbles (just below the surface), resulting in additional dissolution of the surrounding surface forming pitting defects. This problem can be overcome by preventing the gas bubbles from sticking to the surface, by increasing the liquid stirring, or increasing the temperature in order to improve the liquid conductivity. However, stirring should be carefully controlled in order to avoid damaging the viscous layer.

\subsection{Surface brightness}

The degree of surface brightness (luster) is an effective way to establish if the electropolishing was successful in making the surface more planer and free from defects. The non-uniform thickness of the viscous layer over the material surface results in a 
different ohmic resistance from the cathode to the anode. This causes greater dissolution of the protruding features than of recessed features leading to the creation of a uniform surface profile [29]. In the case of the stainless steel (SS 316L) samples produced in this study EDX was used to track the metal/alloy surface composition before and after the polishing, as shown in Figure 12.

The results demonstrate that the removal of the metal/alloy components from the anodic surface is non-uniform and this produces a significant effect. The iron and nickel atoms are more easily removed from the crystal cell than the chromium atoms. Thus, it is possible to say that the electropolishing process is directed preferentially to iron and nickel, leaving the surface rich in chromium. Furthermore, observed effect on the surface (indicating a high chromium content) can be beneficial in some applications, especially where corrosion resistance, friction, as well as mechanical strength are of primary concern.

\section{Conclusions}

In this study it has been found that the electropolishing of SLM stainless steel parts (after re-melting) can achieve a surface texture $(R a)$ of less than 0.5 micron. A significant feature of the process is its ability to target the peaks through preferential dissolution thus providing and efficient and effective method of reducing surface roughness. From the statistical (full factorial 3x3) analysis the best results for surface roughness and minimal defects were obtained when the specimens were kept anodically at current densities associated with potential ranges between 4 to 5.5 volts and maintained at a temperature of $40 \mathrm{C}^{\circ}$.

The overall finding through electropolishing of SLM stainless steel parts in DES type III (choline chloride based) ionic liquids are as follows:

- Polishing is possible across the full range of process variables tested in this study. It is a very effective process for removing the residual oxide scale formed during the re-melting process. It improves the surface finish by more than $60 \%$ compared to re-melted samples.

- The results show that the electropolishing process results in preferential dissolution of the iron and nickel in the SS316L leaving a surface rich in 
chromium, which is beneficial to the mechanical and chemical properties of the surfaces.

- Homogenous dissolution (when optimum parameters are used) indicates the methods can be used to polish additive manufactured samples produced from $\mathrm{Al}$ and $\mathrm{Al}$ alloys, $\mathrm{Ti}$ and $\mathrm{Ti}$ alloys and various cobalt chrome alloys.

- This process offers significant advantages over the existing practice due to the fact that the raw materials are inexpensive; it shows higher efficiency and is environment friendly.

\section{Acknowledgment}

The authors acknowledge Dr. Melanie Petch for linguistic support and the anonymous reviewers for their valuable comments.

\section{References}

[1] R. Sautebin, H. Froidevaux, and D. Landolt, "THEORETICAL AND EXPERIMENTAL MODELING OF SURFACE LEVELING IN ECM UNDER PRIMARY CURRENT DISTRIBUTION CONDITIONS,” J. Electrochem. Soc., vol. 27, no. 5, p. . 1096-1100, 1980.

[2] C. Clerc, M. Datta, and D. Landolt, "On the theory of anodic levelling: model experiments with triangular nickel profiles in chloride solution,” Electrochim. Acta, vol. 29, no. 10, pp. 1477-1486. ', 1984.

[3] D. Landolt, "Fundamental aspects of electropolishing. Electrochimica Acta," Electrochim. Acta, vol. 32, no. 1, pp. 1-11, 1987.

[4] M. Datta and D. Landolt, "Surface Brightening during High Rate Nickel Dissolution in Nitrate Electrolytes,” J. Electrochem. Soc., vol. 122, no. 11, pp. 1466-1472, 1975.

[5] M. Datta and D. Landolt, "On the role of mass transport in high rate dissolution of iron and nickel in ECM electrolytes-I. Chloride solutions," Electrochim. Acta, vol. 25, no. 10, pp. 1255-1262, 1980.

[6] A. P. Abbott, I. Dalrymple, F. Endres, and D. R. Macfarlane, "Why use Ionic Liquids for Electrodeposition ?," vol. 01, 2008.

[7] A. C. Fisher, Electrode dynamics, Oxford University Press. Oxford; New York, 1996. 
[8] P. H. Rieger, Electrochemistry, 2nd edn. Chapman \& Hall, New York; London, 1994.

[9] D. Pletcher, A first course in electrode processes:Texte imprimé, Electrochemical consultancy. Hants, 1991.

[10] P. T. K. and W. R. Heineman, Laboratory techniques in electroanalytical chemistry. Marcel Dekker, Inc., New York, 1996.

[11] H. Jacquet, Figous P, and A, “in French Patent, F. patent, Editor,” 1930.

[12] T. Welton, "Room-temperature ionic liquids. Solvents for synthesis and catalysis,” Chem. Rev., vol. 99, no. 8, pp. 2071-2083, 1999.

[13] A. P. Abbott, G. Capper, K. J. McKenzie, and K. S. Ryder, "Voltammetric and impedance studies of the electropolishing of type 316 stainless steel in a choline chloride based ionic liquid,” Electrochim. Acta, vol. 51, no. 21, pp. 4420-4425, Jun. 2006.

[14] A. P. Abbott, G. Capper, K. J. McKenzie, A. Glidle, and K. S. Ryder, "Electropolishing of stainless steels in a choline chloride based ionic liquid: an electrochemical study with surface characterisation using SEM and atomic force microscopy.," Phys. Chem. Chem. Phys., vol. 8, no. 36, pp. 4214-4221, Sep. 2006.

[15] J. A. Whitehead, G. A. Lawrance, and A. McCluskey, "?Green? leaching: recyclable and selective leaching of gold-bearing ore in an ionic liquid," Green Chem., vol. 6, no. 7, p. 313, 2004.

[16] S. Zhang and Z. Conrad, "Novel properties of ionic liquids in selective sulfur removal from fuels at room temperature. Green Chemistry,” vol. 4, pp. 376-379, 2002.

[17] A. P. Abbott, D. Boothby, G. Capper, D. L. Davies, and R. Rasheed, "Deep Eutectic Solvents Formed Between Choline Chloride and Carboxylic Acids," J. Am. Chem. Soc, vol. 126, p. 9142, 2004.

[17b] Q. H. Zhang, K. D. Vigier, S. Royer and F. Jerome, "Deep eutectic solvents; syntheses, properties and applications", Chem Soc Rev, 2012, 41, 7108-7146.

[18] A. P. Abbott, G. Capper, D. L. Davies, R. Rasheed, and V. Tambyrajah, "Novel Solvent Properties of Choline Chloride/ Urea Mixtures,” Chem. Commun, vol. 70, 2003.

[19] A. P. Abbott and K. J. McKenzie, "Physical Chemistry Chemical Physics," vol. 8, pp. 4265 - 4279, 2006. 
[20] S. Mohan, D. Kanagaraj, R. Sindhuja, S. Vijayalakshmi, and N. Renganathan, "Electropolishing of stainless steel - a review,” Inst Met Finish, vol. 79, pp. 140142, 2001.

[21] K. S. Ryder, “Introduction to Ionic Liquids,” 2008.

[22] K. S. Ryder, "New Sustainable Electrolytes for Metal Finishing and Electropolishing ( aerospace investment castings ).”

[23] A. Abbott, K. . Ryder, and U. Konig, "Electrofinishing of metals using eutectic based ionic liquids,” Inst. Met. Finish, vol. 86, pp. 196-204, 2008.

[24] Alrbaey K., Wimpenny D., Tosi R., Manning W. \& Moroz A.. On optimization of surface roughness of selective laser melting stainless steel parts: a statistical study, J Mat Eng Perform, 2014, 23(6), 2139-2148

[25] A. P. Abbott, N. Dsouza, P. Withey and K.S. Ryder, "Electrolytic processing of superalloy aerospace castings using choline-based ionic liquids" Trans. Inst.Met Finish., vol. 90(1), 9-14, 2012

[26] E.-S. Lee, "Machining Characteristics of the Electropolishing of Stainless Steel (STS316L),” Int. J. Adv. Manuf. Technol., vol. 16, no. 8, pp. 591-599, Jul. 2000.

[27] G. R. Kamat, "Pitting and its Control During Electropolishing of Stainless Steel," Trans. Indian Inst. Met., vol. 40, no. 4, p. page 343-345, 1987.

[28] C.-C. Shih, C.-M. Shih, Y.-Y. Su, L. H. J. Su, M.-S. Chang, and S.-J. Lin, "Effect of surface oxide properties on corrosion resistance of 316L stainless steel for biomedical applications,” Corros. Sci., vol. 46, no. 2, pp. 427-441, Feb. 2004.

[29] D. Landolt, P. Chauvy, and O. Zinger, "Electrochemical micromachining, polishing and surface structuring of metals: fundamental aspects and new developments,” Electrochim. Acta, vol. 48, no. 20-22, pp. 3185-3201, Sep. 2003.

F. Endres, A. P. Abbott and D. MacFarlane, Electrodeposition from Ionic Liquids, Wiley VCH, Weinheim, 2008 


\section{Figures:}

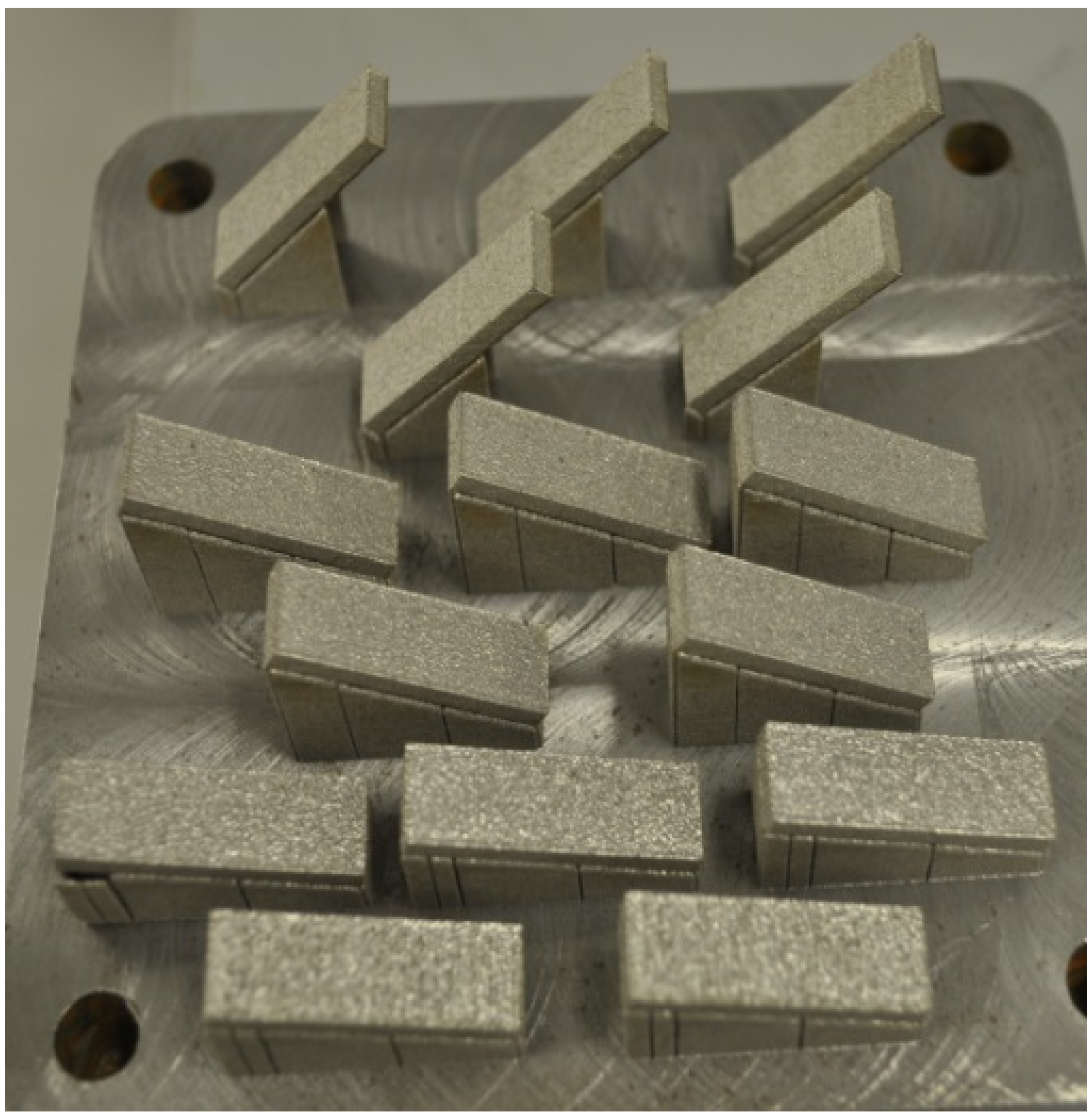

Figure 1. Build samples on the building platform, inclined surfaces $15^{\circ}, 30^{\circ}$ and $45^{\circ}$. 

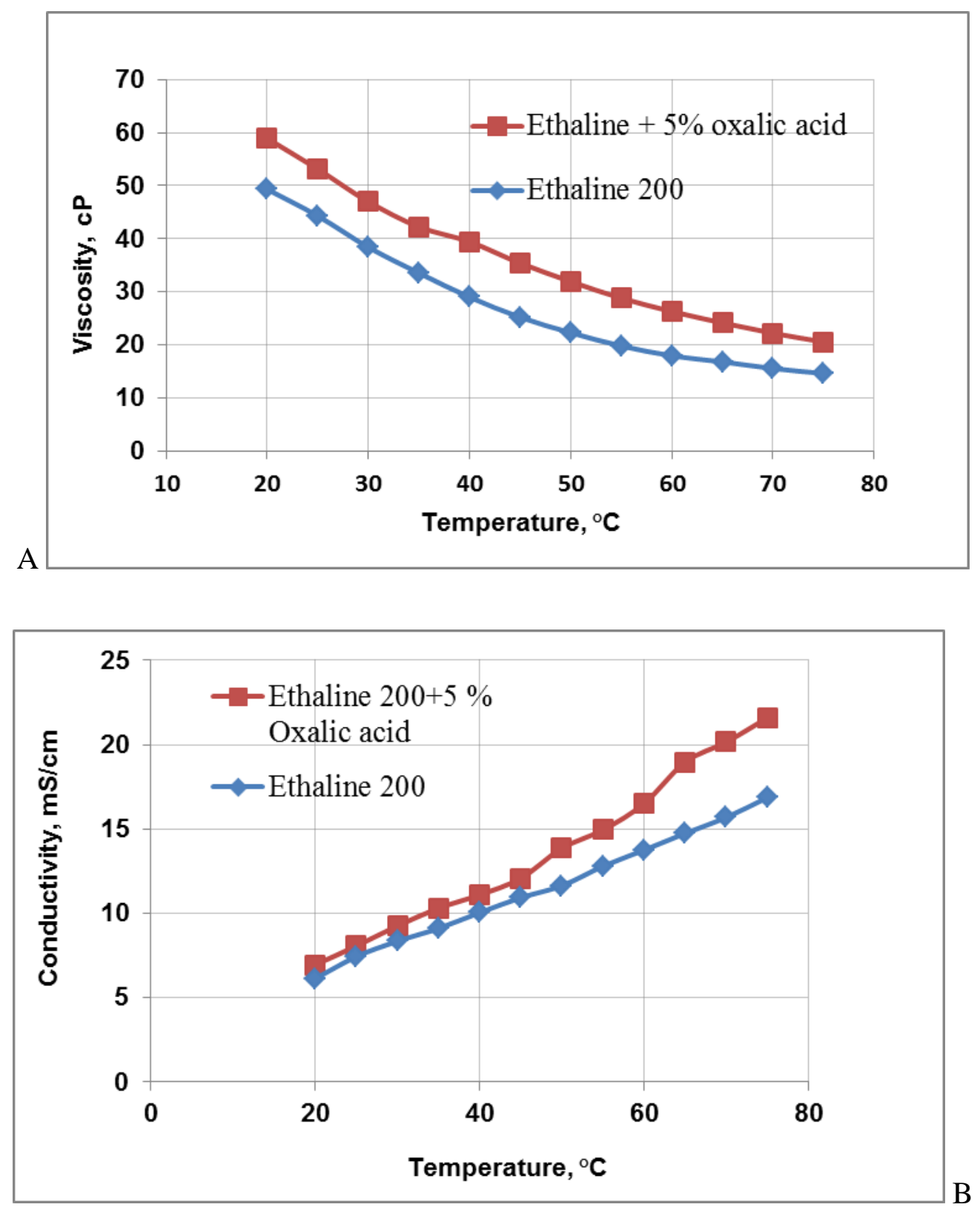

Figure 2. A, Dependence of viscosity on temperatures for Ethaline200 (blue) and Ethaline 200 with 5\% oxalic acid (red). B, Dependence of conductivity on temperature for Ethaline200 and Ethaline 200 with 5\% oxalic acid (red). 


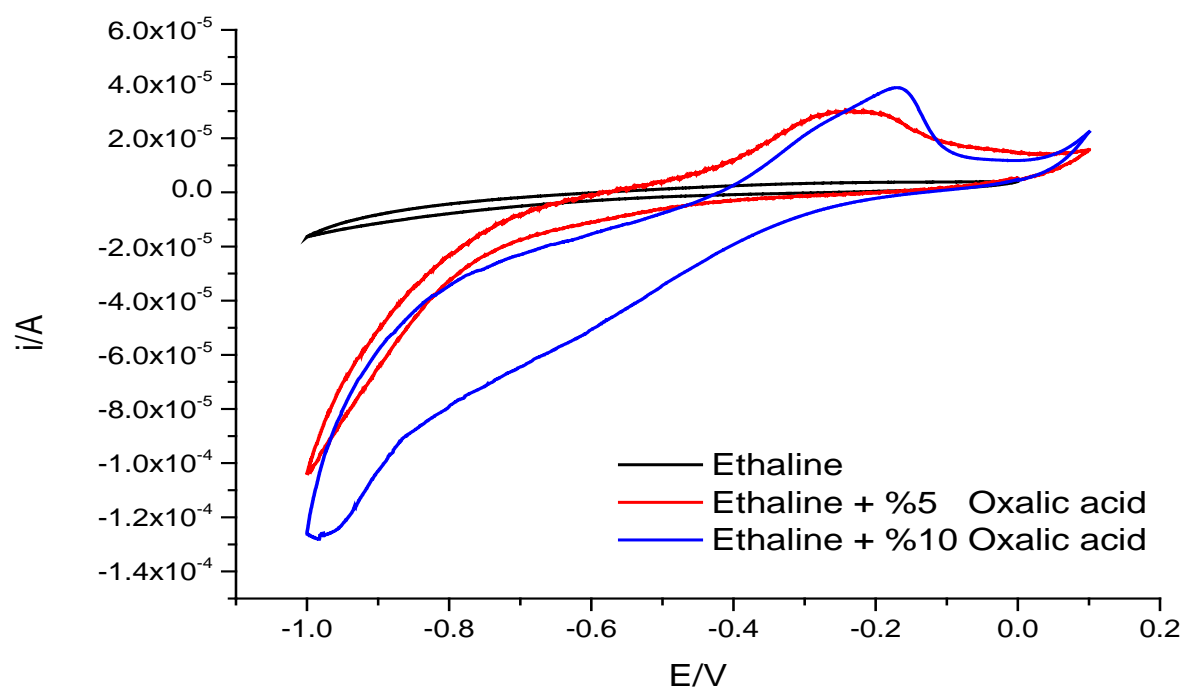

Figure 3. Cyclic voltammetry of Ethalineand Ethaline with 5\% and 10\% oxalic acid. 

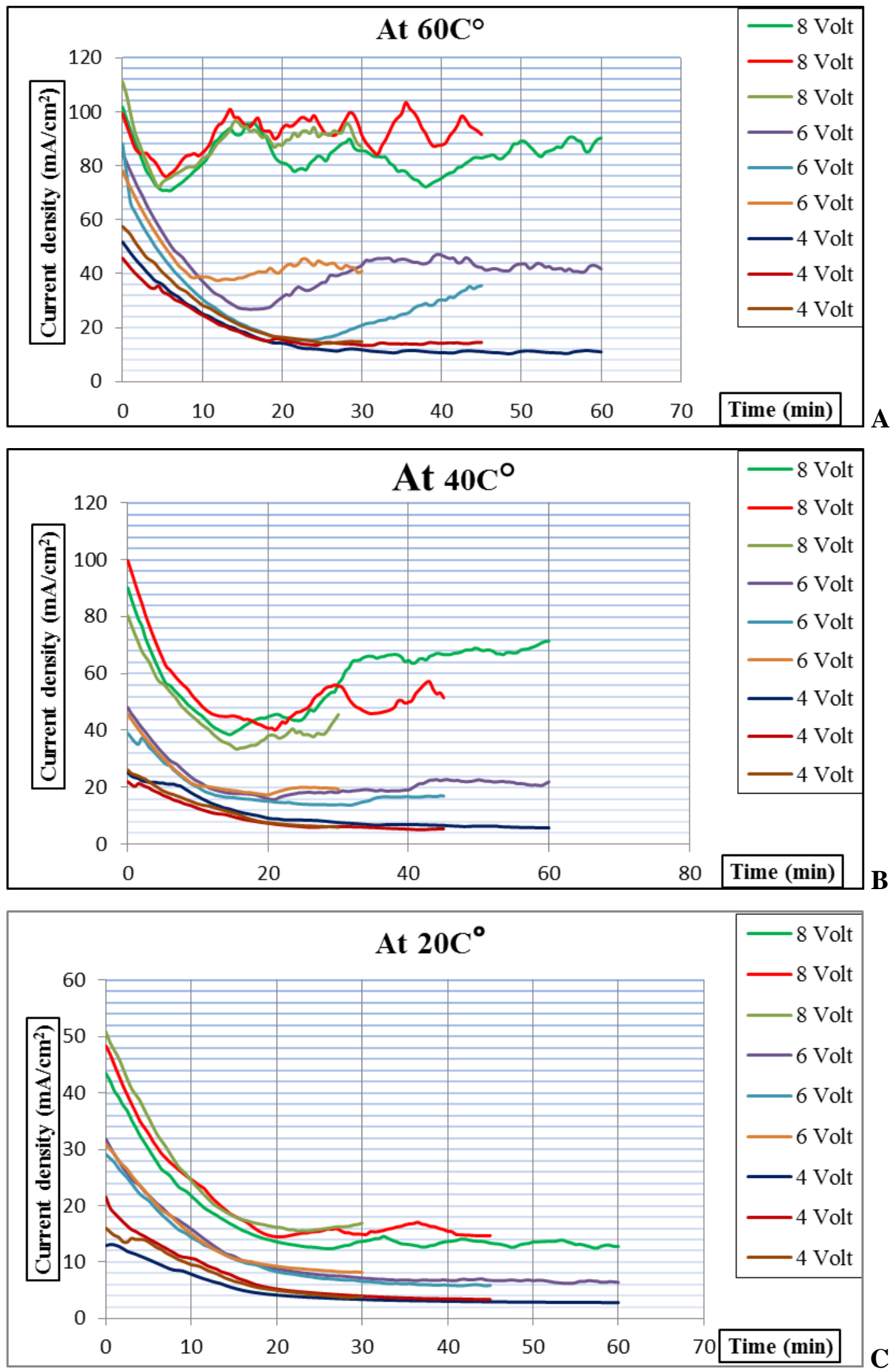

Figure 4. The current density against time for temperatures A, $60 \mathrm{C}^{\circ}$; B, $40 \mathrm{C}^{\circ} ; \mathrm{C}, 20 \mathrm{C}^{\mathrm{o}}$ and 3 different voltages, 8, 6 and 4 Volts. 


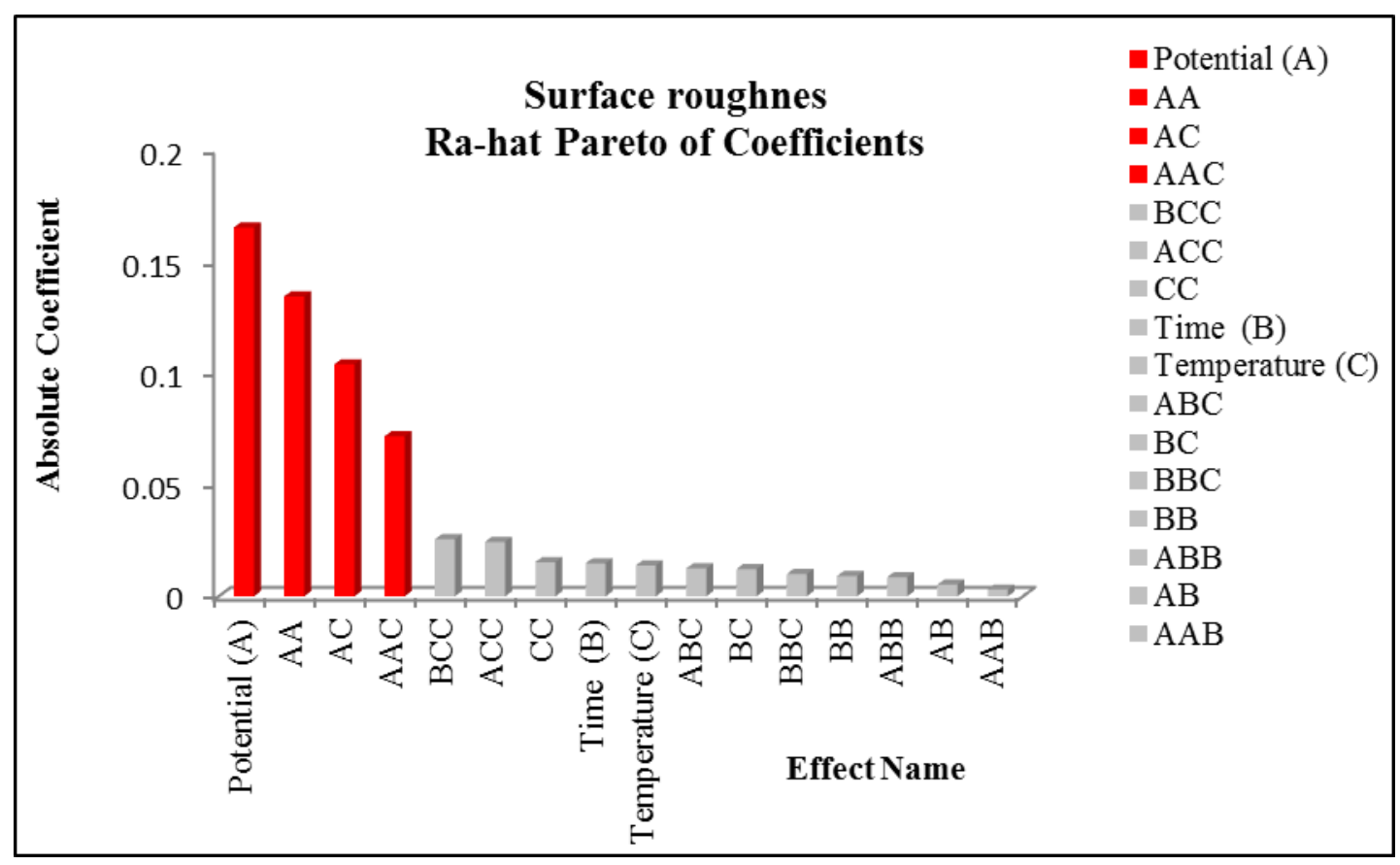

Figure 5. Pareto diagram for predicted average roughness (Ra-hat)

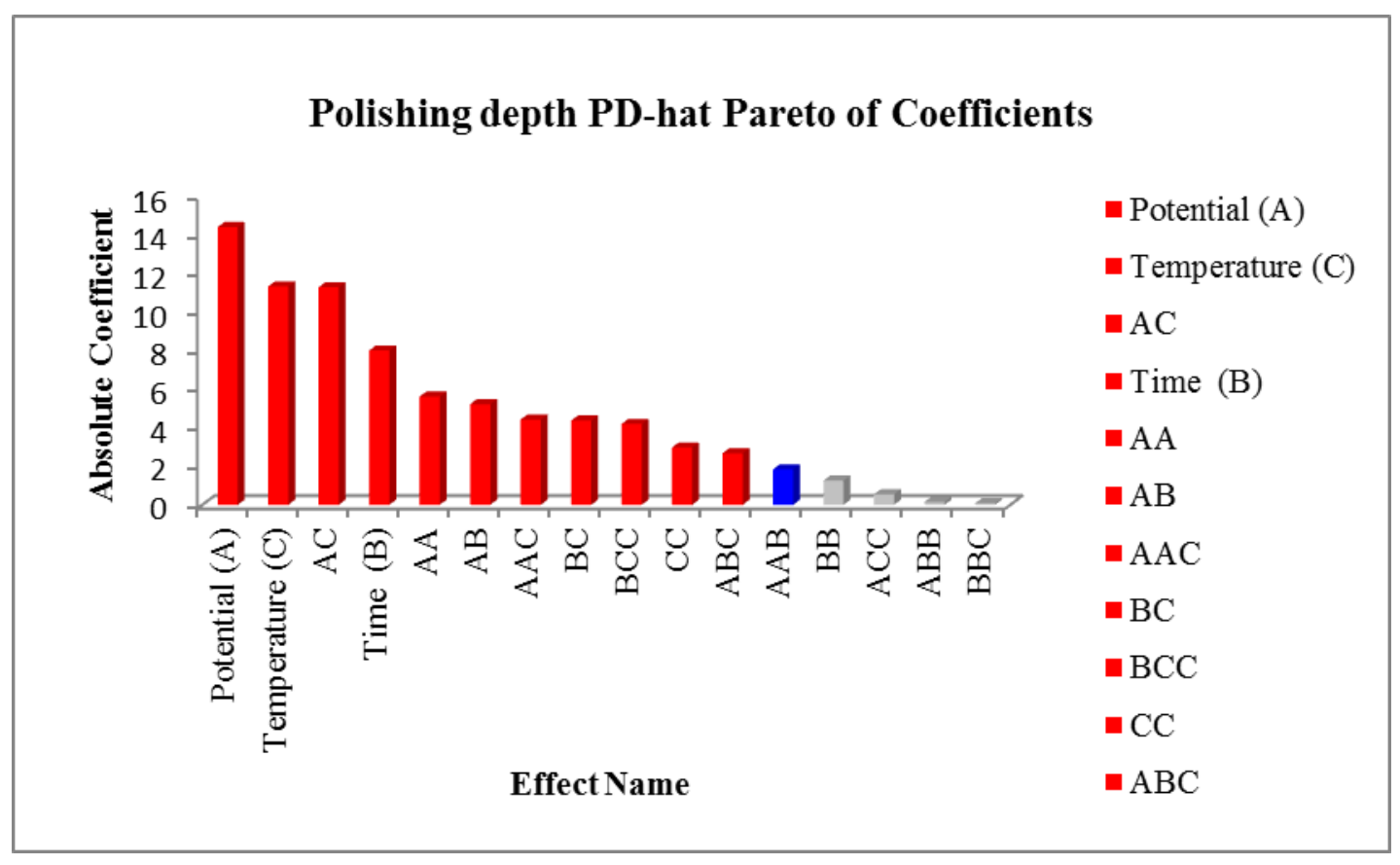

Figure 6. Pareto diagram for predicted polishing depth (PD-hat) 

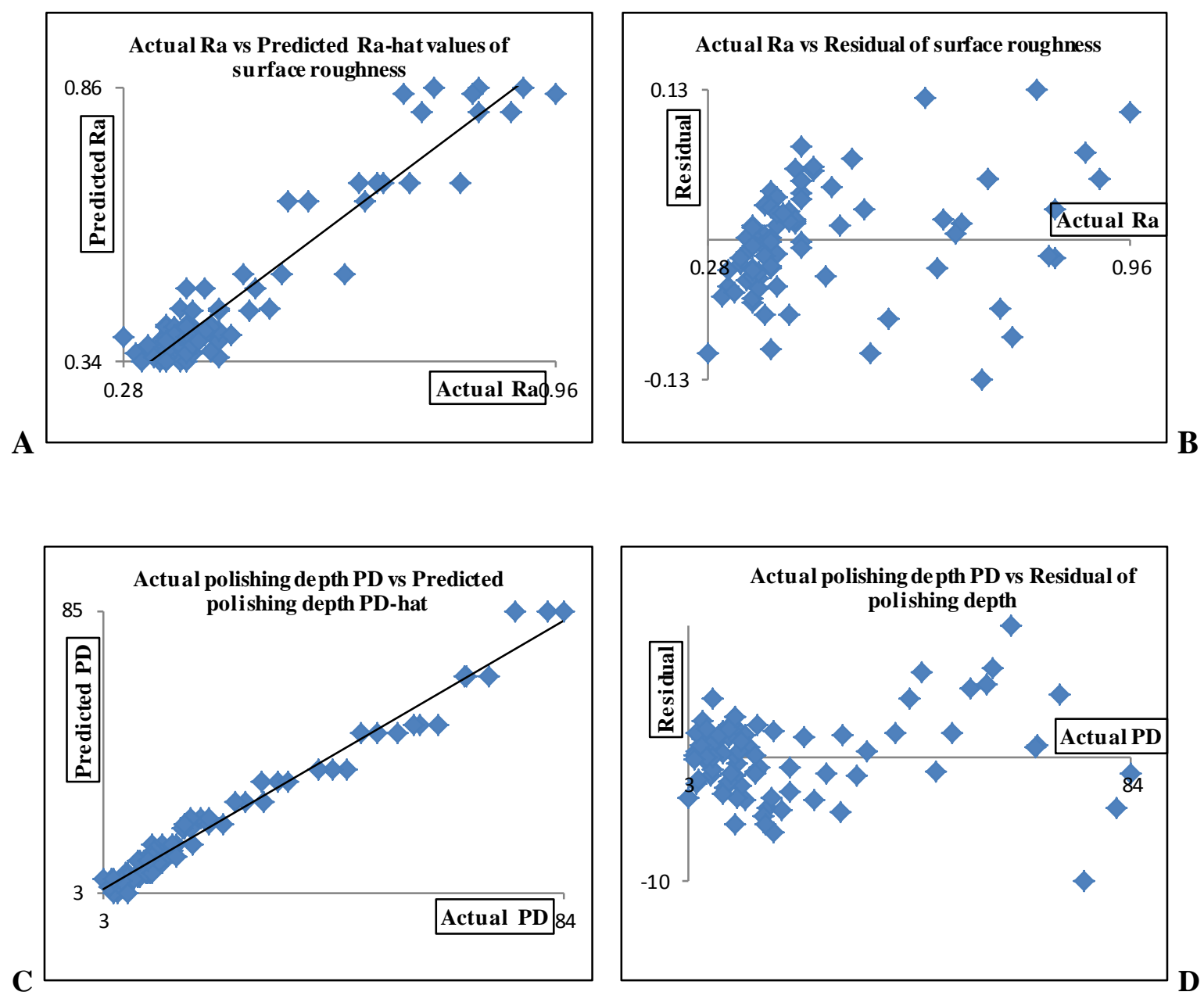

Figure 7. A, actual roughness against predicted roughness and against residual (B). C, actual depth against predicted depth and against residual (D). 


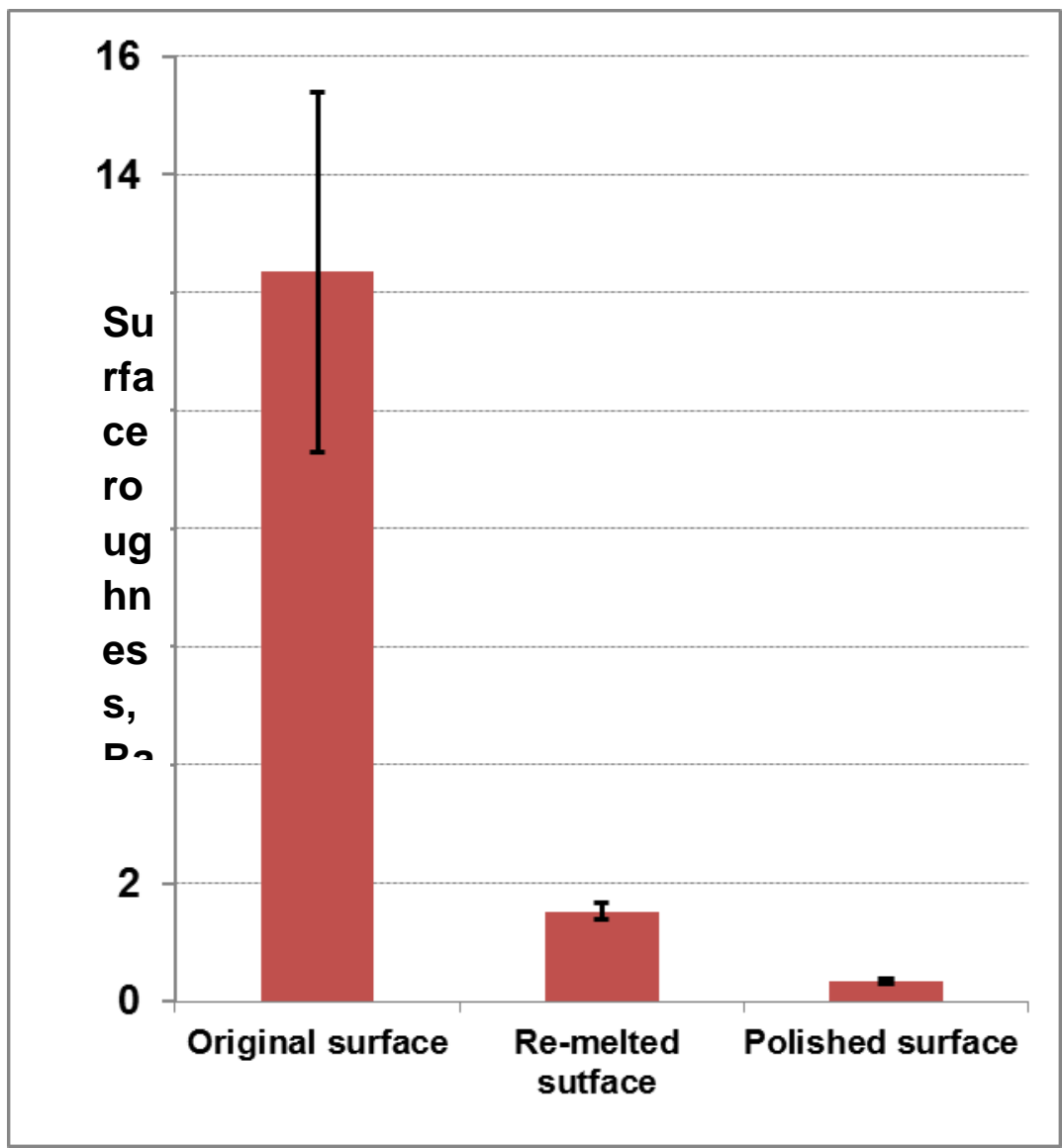

Figure 8: Comparison results of the three stages of surface roughness (Ra, $\mu \mathrm{m})$ 


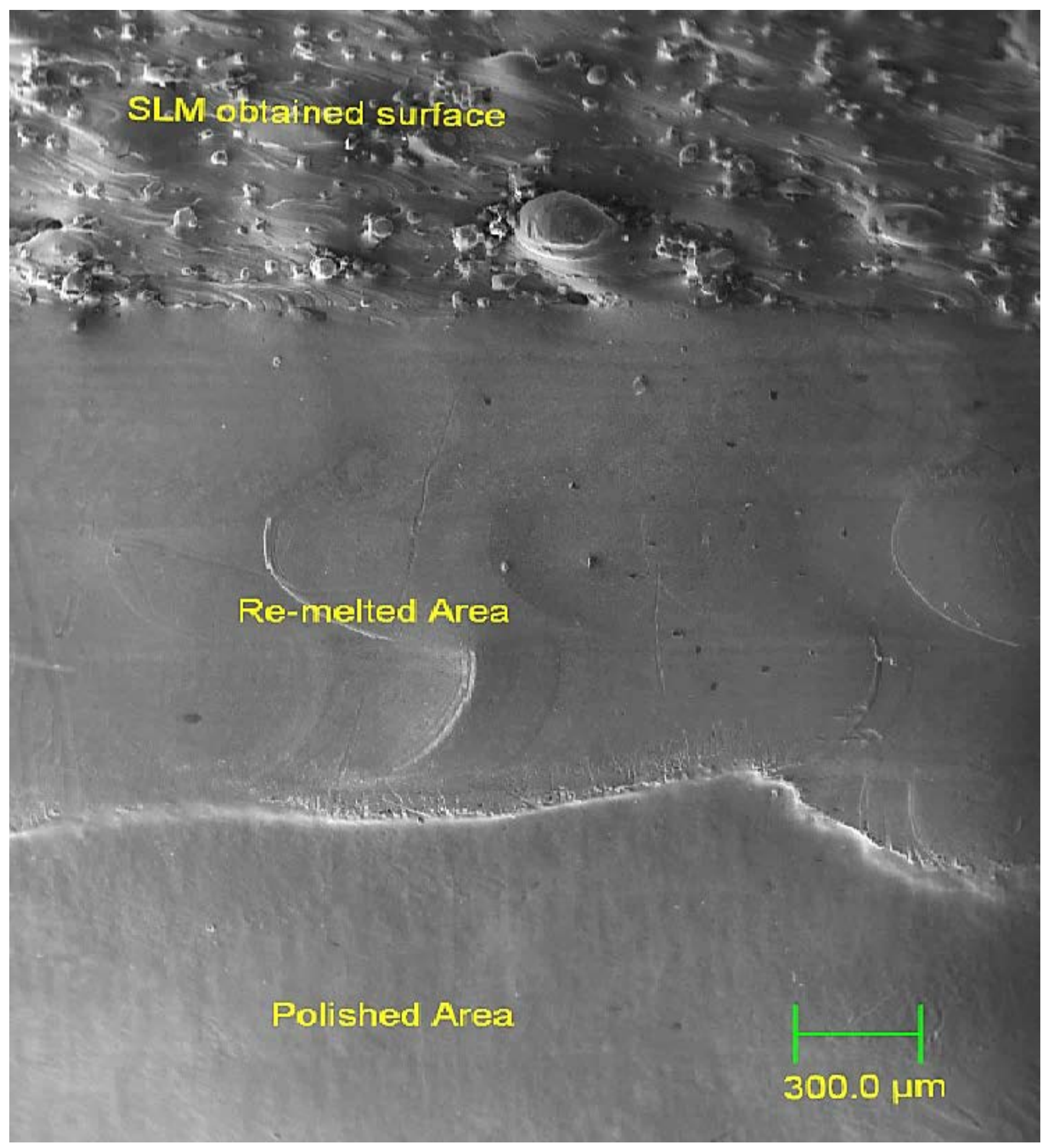

Figure 9. SEM micrograph result of polished sample obtained at $60 \mathrm{C}^{\circ}, 8$ volt and 45minutes. 


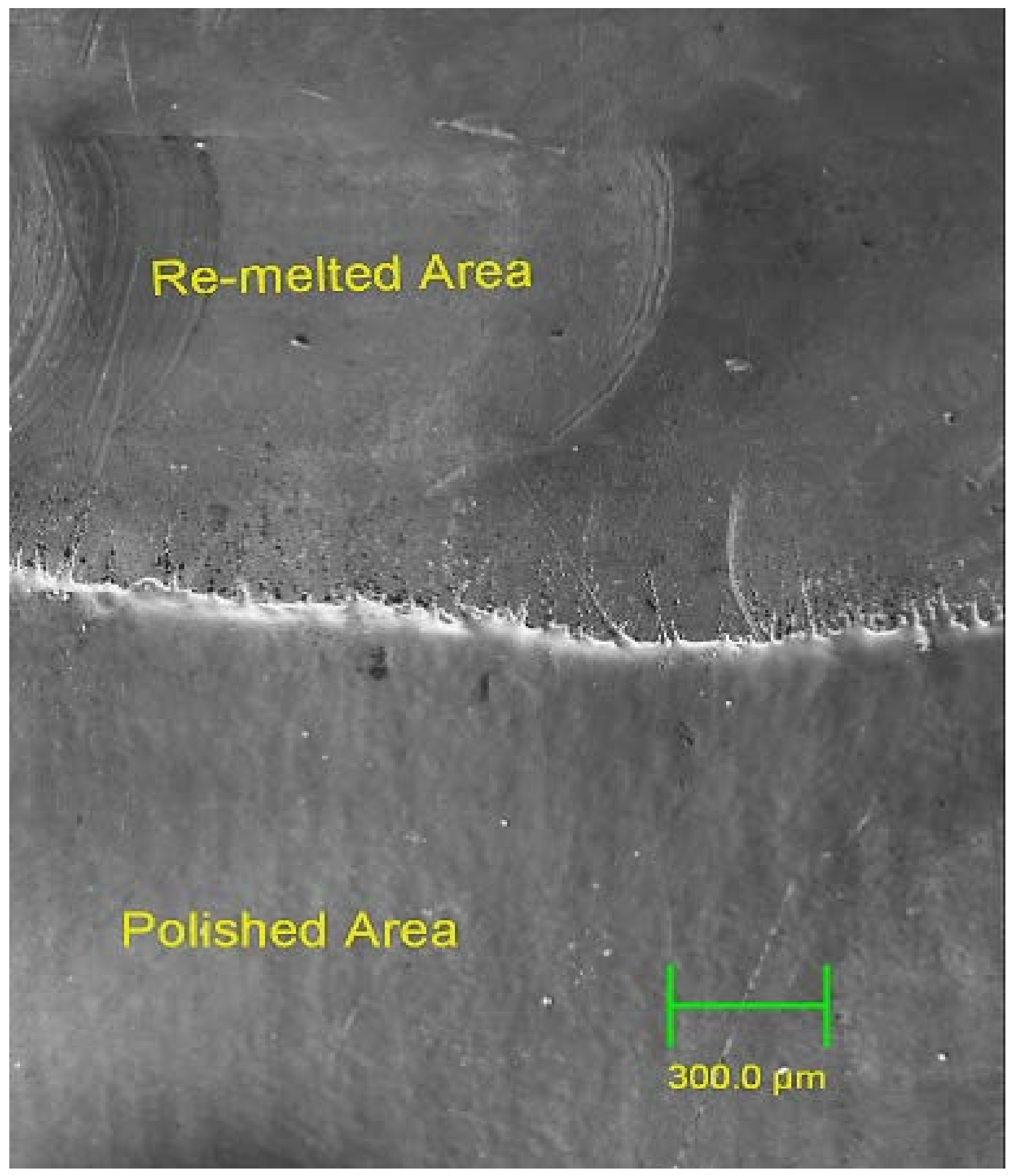

Figure 10A. SEM micrograph result of polished sample obtained at $40 \mathrm{C}^{\circ}$; A, 6 volt, , time interval 45minutes. 


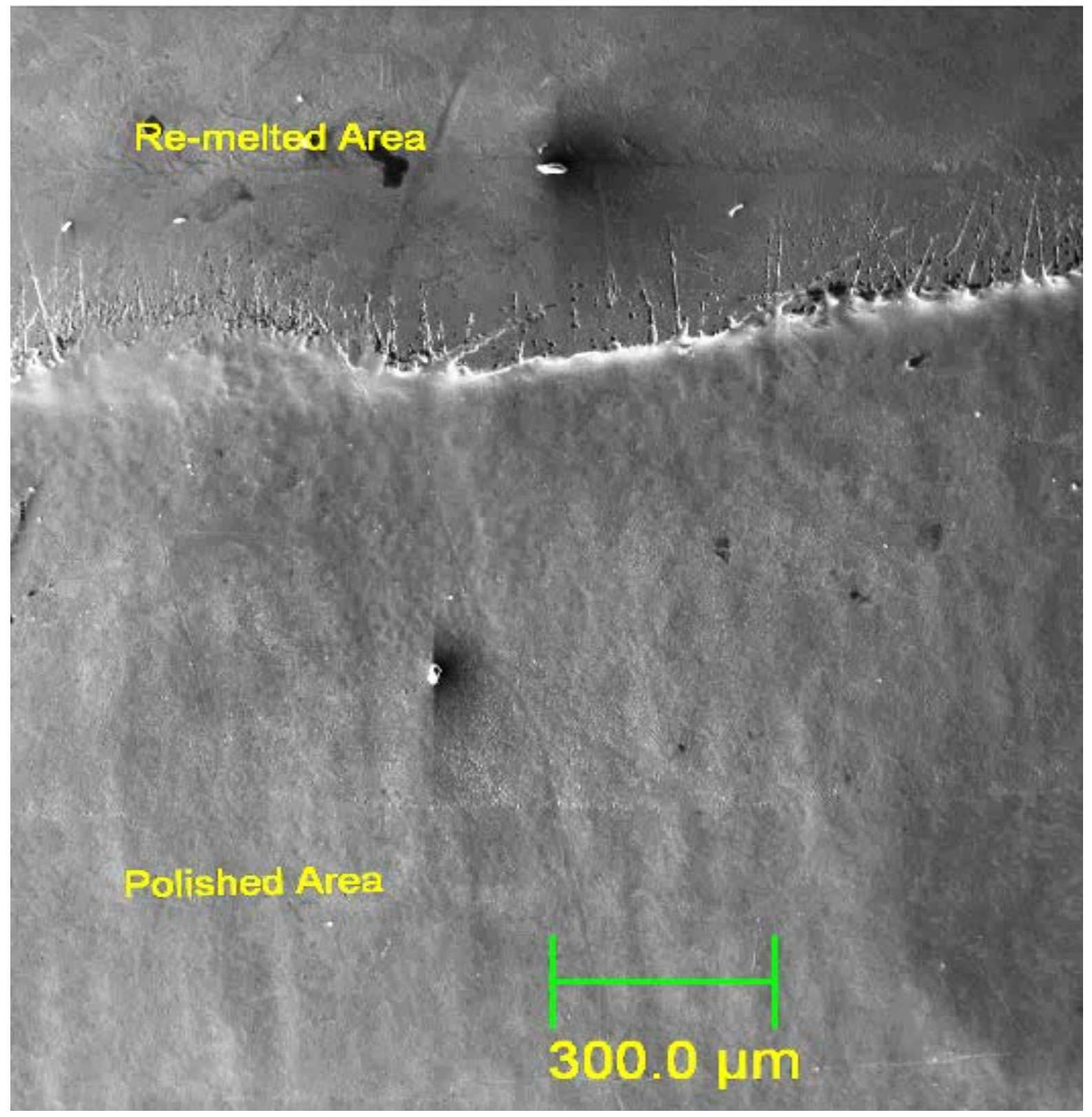

Figure 10B

Figure 10. SEM micrograph result of polished sample obtained at $40 \mathrm{C}^{\circ} ; \mathbf{B}, \mathbf{4}$ volt, time interval 45minutes. 


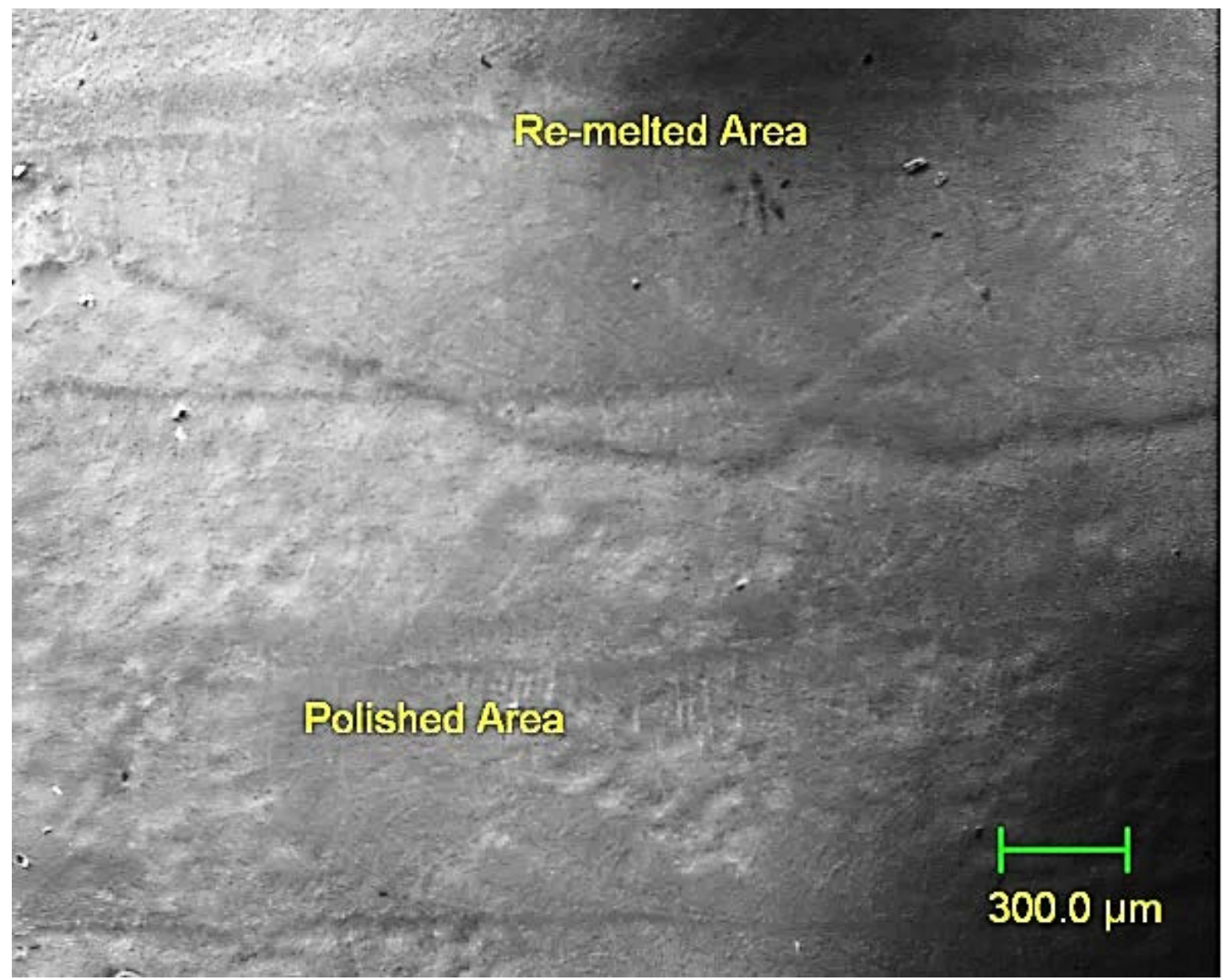

Figure 11. SEM micrograph result of polished sample obtained at $20 \mathrm{C}^{\circ}, 4$ volt and 45minutes. 